\title{
IMPLICAÇÕES SOCIOCULTURAIS E IDEOLÓGICAS DA TRADUÇÃO DE TEXTOS SENSÍVEIS: REFLEXÕES A PARTIR DO PAI NOSSO E SUAS MÚLTIPLAS POSSIBILIDADES DE LEITURA
}

\author{
Cláudio Márcio do Carmo*
}

\begin{abstract}
Resumo: Este trabalho utiliza o recurso explicativo paratexto no caso de traduçoes de textos sagrados, também considerados textos sensiveis dadas as peculiaridades que lhes são inerentes. Construindo um paratexto, procuramos focalizar num primeiro momento diferentes perspectivas de forma a problematizar tanto o processo tradutório quanto as diferentes versões geradas para públicos particulares. Como categoria de análise, optamos pelas escolhas lexicais, por partirmos do pressuposto de que existem implicações socioculturais e ideológicas que subjaz̧em à semântica de cada item lexical escolbido, mostrando qual ponto de vista orientou a tradução, porque essas implicações, muitas vez̧es, são colocadas de maneira mais nítida na forma de um paratexto que possa conduzir o leitor. Como exemplo, produzimos um paratexto baseado numa tradução que se pretende universal para a oração do Pai Nosso segundo Mateus.

Palavras-chave: Paratexto. Tradução. Pai Nosso.
\end{abstract}

\section{INTRODUÇÃO}

A Bíblia, antes de tudo, é o livro sagrado dos cristãos. Ela é formada pelo conjunto dos livros sagrados do Antigo e do Novo Testamento, aceitos por todas as igrejas cristãs como revelação da palavra de Deus. Não obstante o caráter mágico e transcendental que a envolve, existem muitas divergências quanto à tradução de seus textos ou mesmo sobre a autoria dos próprios textos considerados originais.

Em termos tradutórios, a ideia de cânone é muito forte, e apenas mais recentemente tem-se dado importância às diferenças entre

\footnotetext{
* PROMEL/DELAC/UFSJ - Professor Adjunto de Linguística e Língua Portuguesa - Doutor em Linguística Aplicada. Email: claudius@ufsj.edu.br.
} 
traduções como parte integrante de um processo de popularização da Palavra de Deus. No que concerne à ideia de cânone, dentro dos estudos bíblicos, McDonald e Sanders (2002) nos proveem de importante debate.

Nesse sentido, o embate entre estudiosos, teólogos, tradutores, dentre outros, tem-se acentuado e o debate sobre a primazia do textofonte (em hebraico/aramaico e/ou grego) com relação à tradução passa a ser o centro de muitos trabalhos, principalmente no que diz respeito às constantes modificações e adaptações feitas (cf. KALLAND, 1999; NIDA, 2000; MAIER, 2000).

Desses embates, surgem novas perspectivas para o texto sagrado e novos meios são utilizados, dos quais são exemplos as Bíblias multimídia (cf. SISLEY, 2002; MULLINS, 1996; SHEELEY; NASH, 1999). Também se tornam fortes as releituras sob vários pontos de vista: histórico-literário (cf. GABEL; WHEELER, 1993), das relações sociais de poder (cf. CERESCO, 1996), socioliterário (cf. GOTTWALD, 1997), gospel (cf. DUNGAN, 1999), cultural e antropológico, com viés da comunicação intercultural (cf. DEIST, 2000), fundamentalista, judaico, patrístico, popular, feminista/mulherista (cf. CIPRIANI et al. 2000), contrastivo da visão judaica com a cristã (cf. BARRERA, 2000), homossexual (cf. HELMINIAK, [1994] 2000; BAYLY, 2002), socioantropológico (cf. SILVA, 2000), afrocêntrico e/ou negro (cf. FRISOTTI, 1995, 2002; PIRES, 2002; MUGAMBI, 2002), ecológico (cf. REIMER, 2004), o indígena (cf. SILVA, 2005), dentre outros.

Neste trabalho, não pretendo ter um ponto de vista específico, embora a neutralidade em si não exista, pois partimos sempre de um lugar social, estamos sempre situados em um tempo e em um espaço, somos sempre fruto do meio em que vivemos. Contudo, é possível traçar metas e formular hipóteses, priorizando não o que se pensa sobre o texto, mas aquilo que se materializa ou pode se materializar em termos ideológicos nele. Por isso, construindo um paratexto e refletindo sobre as escolhas lexicais feitas no processo tradutório em sua relação com os possíveis pontos de vista e efeitos de sentido produzidos, podem-se tornar explícitas algumas das diferentes visões de mundo materizalizadas num texto que, no caso específico deste trabalho, possui um valor para além das diversas orientações que constroem grupos sociais e ajuda na 
coesão entre seus membros e entre outras culturas que consideram o Pai Nosso uma das mais relevantes orações cristãs.

O texto em que nos baseamos para nossas reflexões é uma versão do Pai Nosso segundo Mateus. Visando à universalização da Bíblia, a tradução é feita por João Ferreira de Almeida para a língua portuguesa e distribuída internacionalmente por um grupo que se autointitula $O s$ Gideões Internacionais. Esse grupo compõe uma associação de homens de negócio e profissionais liberais cristãos, os quais buscam tornar conhecido o evangelho de Cristo no mundo inteiro.

Para organizarmos nossas reflexões, procuramos analisar questões referentes (1) aos estudos da tradução e perspectivas sobre a tradução do texto sagrado, entendendo que se trata de uma tarefa complexa por envolver inúmeras variáveis; e (2) ao Pai Nosso no que diz respeito a uma orientação exegética em termos da relevância de uma revisão e crítica da tradução. Posteriormente, tentamos construir um paratexto para a tradução do Pai Nosso escolhido, tentando verificar, nas escolhas lexicais, tentativas de universalização e apagamento de ponto de vista, bem como procurando, sempre que possível, mostrar pontos em que outras traduções se apegaram para perspectivação de suas traduções. Seguem-se as considerações finais e as referências bibliográficas.

\section{ESTUDOS DA TRADUÇÃO E PERSPECTIVAS SOBRE A TRADUÇÃO DO TEXTO SAGRADO}

Os trabalhos de Nord (1997), Tymoczko (1998) e Maier (2000) são extremamente relevantes para o esclarecimento do processo tradutório por fazerem um apanhado geral sobre a história dos Estudos da Tradução e (re)constituírem um percurso para essa disciplina, mostrando que, no início, havia uma prioridade da forma sobre o conteúdo, provinda da busca de equivalência lexical entre a língua-fonte e a língua de chegada (alvo).

$\mathrm{Na}$ perspectiva desses estudos, priorizava-se a equivalência entre texto-fonte e alvo, o que levava a alguns problemas como a primazia do texto fonte; a desconsideração de aspectos culturais; a falta de conceitos bem definidos; diferenças nos padrões de tradução; busca de universalidade, que não reproduzia aspectos específicos de outras 
culturas; exclusão de textos na língua-alvo que não satisfizessem os padrões da língua fonte; e elevação da fonte como padrão (cf. NORD, 1997).

Isso é relevante porque, mesmo havendo alguma equivalência nas escolhas lexicais, essas escolhas são feitas, muitas vezes, com a função de levar à comunidade de recepção os pontos de vista da Instituição de que parte. Esse procedimento de escolhas lexicais não é neutro e mostra que é relevante levar em conta outros fatores no processo da tradução, sejam eles culturais, religiosos ou sociais, uma vez que podem gerar diferentes interpretações.

Gabel e Wheeler (1993, p. 220), especificamente em relação ao objeto aqui em análise, chamam a atenção para o fato de muitos leitores dependerem das traduções e explicam que, nesse caso, depender da tradução é depender de algumas qualidades dos autores da tradução, tais como o seu conhecimento das línguas originais da Bíblia, de suas culturas, dos sistemas religiosos e das situações históricas que produziram os textos considerados originais. Os autores chamam a atenção também para o grau de compromentimento com a objetividade, a habilidade e a imaginação quando o tradutor usa da língua de chegada e, por fim, para a conciência desse tradutor quanto à "real" natureza do próprio processo de tradução.

Dentro dos estudos da tradução bíblica, outro ponto crucial de discussão refere-se não especificamente ao processo de tradução do texto em si, mas ao conceito de sagrado. Nesse sentido, Simms (1997) e Bryant (2002) nos trazem questionamentos e pontos de vista interessantes, porque, num primeiro momento, convergem e, em outro, separam-se a partir de uma mesma linha de pensamento.

Para a conceituação de texto sagrado, Simms (1997) busca subsídios nos estudos linguísticos a partir das diferenças entre denotação e conotação. $\mathrm{O}$ autor contrasta uma primeira ideia de um mundo que deveria ser percebido de acordo com proposições lógicas, calcadas na denotação, com uma outra advinda do filósofo Wittgenstein, a partir da qual a proposição é vista como uma pintura da realidade. Tal discussão serve para que o autor trabalhe seu pensamento de que viver no mundo como um animal que fala depende bem mais de conotações de palavras que de suas denotações, como no caso dos textos sensíveis. Logo, existe 
aqui um ponto a ser contestado no discurso matemático que sustenta o ideário da denotação em detrimento de outras formas de percepção. Os textos sensíveis seriam então um problema sociossemiótico que emerge principalmente no momento da tradução, que envolve repalavreamento.

Nesse sentido, tem-se, por um lado, a emergência de um discurso de sustentação da fidelidade do texto-fonte e outro que assevera a tradução livre que precisa trabalhar com conotações e equivalentes culturais, para preencher as expectativas dos leitores para os quais um texto é traduzido. Por isso, uma tradução livre torna-se uma tradução cultural, ela busca equivalência de significado e não equivalência de palavras, sendo também, por esse motivo e nesse sentido, considerada mais democrática.

Dentro desses aspectos culturais, percebe-se o envolvimento com as diferenças culturais, com aspectos éticos, raciais, institucionais, políticos, legais, de gênero social e do estado. Essas diferenças impõem restrições relevantes para que embates intergrupais não ocorram. E é por isso que a funcionalidade - a preocupação em resguardar a equivalência funcional dos itens - é importante, para acurar substituições semânticas que ajudarão em todos os sentidos a buscar credibilidade para o texto traduzido, para que não haja problemas com o seu desempenho na comunidade de recepção. Simms (1997), por exemplo, busca nas notas de rodapé a solução para problemas relacionados às diferenças supracitadas, pois nelas poderão ocorrer explicações extratextuais, que fazem visível o tradutor, ou seja, fazem dele não apenas um tradutor, mas também produtor de um novo texto.

Nesse ponto, Simms (1997, p. 19) define os textos sagrados esclarecendo que "o que faz com que sejam sagrados é a crença em que eles expressam as intenções do Autor Original, [ou seja] que o 'autor do texto' é apenas um escriba, alguém que transcreve uma Palavra original com a qual está inspirado.” Essa explanação leva-nos a perceber que, no caso da Bíblia, estamos diante de um texto sensível que ganha vida a partir das diversas interpretações que são feitas dele e no processo da tradução. Como explica o autor, o poder do Divino Espírito Santo dissolve a distinção entre o literal e o metafórico. Logo, os apóstolos são apenas mediadores. 
Não obstante, para Bryant (2002), as interpretações são muitas e dão vida aos textos sagrados. Após a leitura atenta do Tao-te-ching ${ }^{1}$ e depois de ler várias outras versões desse texto, o autor percebeu que havia muitas interpretações e que elas eram muito diferentes, razão pela qual vários estudiosos dedicaram suas vidas a procurar mentiras na tradução e interpretação desses textos, partindo de um ponto de verdade. Com um pensamento bastante próximo do de Simms, Bryant mostra que ocorre uma mudança de conotação e de contexto o tempo todo e a meta de muitos intérpretes é ver através do texto um significado espiritual e libertar esse significado para pesquisadores de seu tempo e de sua língua.

A visão com que Bryant (2002) quer se opor a esse pensamento é humanista. Para ele, o que faz sagrado um texto é o fato de nós não sabermos quem o escreveu, nem termos acesso à versão original, o que se aproxima da ideia de Simms. Contudo, Simms ainda parece mostrar um pensamento mais tradicional: de que, apesar da liberdade em termos tradutórios, existe certo e errado em algumas traduções. Bryant acredita que as muitas traduções e interpretações são benéficas, que podemos escolher algumas, compará-las e, mais que isso, estendê-las, filtrando-as, no sentido de que as compreendemos e selecionamos a partir de nosso olhar pessoal e de nossa própria visão de mundo. Talvez esse seja um ponto de vista inovador e que se diferencia bastante das ideias de Simms.

Como nos esclarece Bryant, ele está interessado na perspectiva adicional que essa tentativa provê, pois não lhe interessa uma versão definitiva. Destaque-se que esse autor descreve o texto sagrado valendose de um dito hebreu que propõe uma leitura coerente com diferentes momentos da vida. De acordo com esse dito, o jovem, na leitura do texto, desenvolveria sua liberdade textual que pode provê-lo de orientação moral e léxico espiritual. $\mathrm{O}$ mais maduro se beneficiaria dele começando a ver suas falhas e o que deve ser preservado. $\mathrm{O}$ velho, por sua vez, com uma visão bem mais amadurecida, pode interpretar o texto e, talvez, estendê-lo, fazendo conexões que, anteriormente, não poderia fazer devido a limitações advindas de sua experiência de vida, que era

${ }^{1}$ Livro da doutrina taoísta (Taoísmo) que contém os ensinamentos de Lao Tsé, o qual é composto de 81 aforismos e representa para o povo chinês o que os ensinamentos de Jesus representa para o mundo ocidental. Tao Te Ching é comumente referido como O Livro do Caminho e da Virtude. (cf. http://www.taoismo.org.br/stb/index.php).

CARMO - Implicações socioculturais e ideológicas... 
mais restrita. A característica unificadora residiria não na palavra de Deus ou na coerência da visão, expressão, ou tema, mas nos versos e estórias espirituais que os sábios das diversas culturas não querem perder.

Independentemente das diferenças entre os povos e entre as interpretações, as estórias são tomadas como símbolos espirituais das culturas. Como afirma Bryant (2002), o conceito de Bíblia é fechado não por Deus, mas pelos líderes da Igreja Católica. Cabe-nos salientar que essa ideia de texto sagrado supera a de Simms e embasa todas as interpretações modernas dos textos sagrados, sob diversas perspectivas, conforme expusemos na introdução deste artigo.

Gohn (2001), por sua vez, posiciona-se criticamente revendo conceitos como funcionalidade, intencionalidade e conceitualização na tradução de textos sagrados. Segundo o autor, funcionalidade pode ser entendida como "a preocupação em procurar resguardar, na língua de chegada, a mesma função que o texto de partida tem na língua de origem [ou seja] uma equivalência funcional" (p.151), e critica o posicionamento de pesquisadores que afirmam que se deve considerar "a intencionalidade e o objetivo comunicativo do 'autor' sagrado (se é que se pode falar de um 'autor' para os textos sagrados)" (p.152).

Nesse sentido, os paratextos que orientam a leitura das diferentes traduções podem constituir importante recurso no processo de tradução de textos dessa natureza e podem ser considerados ambientes ricos para a pesquisa e a crítica da tradução. Por isso, neste trabalho, construímos um paratexto e orientamos nossas reflexões partindo das escolhas lexicais, como "portas de acesso" às diferentes visões de mundo que subjazem a elas.

\section{O PAI NOSSO: ORIENTAÇÃO EXEGÉTICA, REVISÃO E CRÍTICA DA TRADUÇÃO}

Tendo em mente a ideia de texto sagrado exposta resumidamente na seção anterior, podemos iniciar nossas reflexões a partir da construção de uma proposta de paratexto para a oração do Pai Nosso, partindo não da oração, mas de uma orientação exegética que nos ajude a clarear e situar o contexto em que esse texto se encontra no conjunto de manuscritos do Novo Testamento. A ideia de paratexto que tomamos 
como referência é a de um conjunto de enunciados que contornam um texto, procurando ajudar o leitor no processo interpretativo (para mais esclarecimentos, ver MAINGUENEAU, 2000).

Esse procedimento é relevante, pois os paratextos podem ser considerados os lugares ideais para encontrarmos as orientações e dificuldades encontradas no processo de tradução. Goddard (1999), por exemplo, analisou e explicou o sistema de notas de tradução da Bíblia New International Version (NIV), buscando pôr em evidência os artifícios utilizados no esclarecimento principalmente dos epítetos e jogos de palavras nos textos originais, o que muitas vezes só pode ser feito dessa forma, ou seja, na forma de paratexto.

A oração do Pai Nosso pode ser encontrada nos evangelhos de Mateus (6, 9-13) e Lucas $(11,2-4)$ e se insere nos momentos em que Jesus procura transmitir a seus discípulos maneiras de orar, sendo que, dentro do conjunto textual onde a encontramos, temos um contexto de regulamento das ações.

Como Fiores e Goffi (1989) nos esclarecem, existem algumas diferenças entre essa oração em Mateus e em Lucas: enquanto Mateus faz uma vinculação estreita entre a oração e as atitudes que devem acompanhá-la, Lucas a situa como resposta de Jesus à súplica de um de seus discípulos, quando Lhe pede uma maneira para orar. Segundo esses autores, "o Pai-nosso reflete claramente o pensamento de Jesus sobre a oração, embora seja impossível determinar hoje com precisão suas palavras exatas" (FIORES; GOFFI, 1989, p. 879). Nesse sentido, parece residir aqui um ponto crucial das divergências tradutórias, pois, embora já exista um esforço em contrário, ainda há uma primazia da fonte, que, como se vê, nem sempre é precisa e livre de dúvidas. Fiores e Goffi afirmam que a fórmula de Lucas está mais próxima que a de Mateus da expressão original, mas que este ponto não é aceito unanimemente pelos exegetas.

Na Bíblia de Jerusalém (1985), em nota de rodapé, página 1848, existe um esclarecimento de que há uma diferença de dois pedidos a mais constantes em Mateus. De acordo com essa nota, há uma predileção em Mateus pelo número sete e talvez tenha sido com o objetivo de conseguir sete pedidos que Mateus acrescentou ao texto básico (como se verifica em Lucas 11, 2-4) a terceira e a sétima petições. 
Chevalier e Gheerbrant (2001, p. 826-831) fazem relevante análise do número sete e de seu caráter mágico e transcendental reincidente em várias culturas. Como se trata de tradução de um texto sagrado, a presença do número sete pode inclusive ser um ponto de aproximação entre culturas que, num primeiro momento, poderiam não ter contato.

Há também que se refletir sobre a questão de originalidade, quando está sendo pressuposta a interpretação do texto e sobre o termo 'fórmula', que se tornou atualmente um primeiro elemento de distinção entre algumas igrejas cristãs como a Católica e os vários grupos evangélicos. Enquanto as primeiras aceitam fórmulas (orações, ladainhas, novenas, trezenas etc.), os diversos grupos evangélicos procuram orar sem fórmulas ${ }^{2}$, procurando estabelecer, mais que qualquer outra coisa, um diálogo interior com Deus (cf. FERNANDES et al., 1998; CARMO, 2001).

Essas diferenças são relevantes na sinalização dos motivos para as escolhas tradutórias, pois, conforme Maier (2000), Revisão e Crítica da Tradução é uma área responsável por avaliar as publicações de traduções literárias ou não. E, de acordo com a autora, essa área, apesar de toda sua relevância, demorou a ser reconhecida, tendo sido considerada à parte da prática da tradução e, às vezes, um elemento de ligação entre teoria e prática da tradução. Deve-se ressaltar que a Revisão e Crítica da Tradução passou por momentos históricos específicos, começando apenas com críticas, na maioria das vezes pessoais, tendo como referência o texto original e classificando a tradução como boa ou ruim. Esse contexto levou vários autores a fazerem revisões não só de obras, mas desse histórico. Contudo, a autora mostra que é possível perceber inimizades, que estão fora de uma avaliação criteriosa da tradução.

Nesses termos, emerge um grupo de teóricos que formula hipóteses, tendo como referência um conceito de descrição pura, que prioriza os elementos formais, e outro que percebe a relevância da adoção de uma postura mais aberta. No primeiro caso, o conceito de equivalência toma força, trazendo, sobretudo, uma ideia de primazia do original sobre as traduções.

\footnotetext{
${ }^{2}$ Salmos, perícopes, dentre outras fórmulas, são, para os evangélicos, apenas um ponto de partida para o diálogo com Deus, não a oração pronta como se considera em outras religiões.
} 
Maier (2000, p. 208-209) mostra que é importante redefinir os conceitos e encarar o processo da tradução como envolvendo algo além do linguístico, aceitando inclusive diferentes versões para o mesmo texto, bastando para isso que haja uma prática avaliativa criteriosa e consciente, inclusive de aspectos culturais, raciais, identitários, religiosos, dentre outros, que estiverem em jogo no processo tradutório.

No caso da tradução de textos sensíveis, como o Pai Nosso, uma perspectiva mais eclética como a mostrada pela autora é relevante, uma vez que ele é traduzido para muitas línguas e muitos dialetos, assim como para culturas próximas e distantes, o que leva o tradutor a ter que, no mínimo, conhecer e levar em conta sempre duas culturas diferentes que estarão se unindo. E, nesse espaço dialético, as escolhas lexicais são relevantes e construtoras de formas de ver, pensar e agir, ou seja, visões de mundo, pensamento/crença e ação/atitude. Por isso, há diferenças provenientes principalmente do ponto de vista de que derivam as diversas interpretações do Pai Nosso, uma vez que é incontestável o seu valor e a sua transcendência unificadora para além de diferenças rituais, sociais, culturais e ideológicas.

\section{OS TERMOS DO PAI-NOSSO: CONSTRUINDO UM PARATEXTO}

\section{Pai Nosso:}

Dentre todas as palavras utilizadas na oração do Pai Nosso, talvez a mais comentada e estudada seja a palavra Pai, pois, proveniente da escritura em aramaico, Abba (pai), as interpretações dessa palavra têm suscitado muitas discussões.

De acordo com Fiores e Goffi (1989, p. 880-881), todas as orações do Senhor que se conservaram até nossos dias começam com essa palavra, embora esclareçam que ela só aparece textualmente em três passagens neotestamentárias (Mc 14, 36; Rm 8,15; Gl 4,633). Segundo os autores, esse termo já estava relacionado com o de criador e se

\footnotetext{
${ }^{3}$ Embora estejam claras como passagens do Novo Testamento, tais abreviaturas não constam, por extenso, da lista inicial desse dicionário.

CARMO - Implicações socioculturais e ideológicas...
} 
diferenciava do conceito de paternidade atribuído a Iabweh em Israel, por este estar marcado pela ideia de soberania.

Enquanto a ideia de paternidade divina não passava de uma espécie de predileção de Iahweh para com seu povo, parece que Jesus utilizou um termo próprio para designar Deus: $A b b a$. Nesse sentido, a categoria de filiação utilizada por Jesus não fala de Pai por ser de Israel ou do mundo, mas por este criador e redentor (goel) ser pensado como Deus. Quando Mateus acrescentou o possessivo nosso, formando a expressão Pai Nosso, havia uma preocupação litúrgica que procurava estender a paternidade de Deus a todos que deveriam acolher e seguir os ensinamentos de Jesus.

Vale apenas ressaltar um ponto que pode estar intimamente relacionado à proposta feminista/mulherista de leitura da Bíblia. Segundo Fiores e Goffi (1989, p. 881), na dificuldade de se saber se o termo Pai é a melhor palavra para traduzir em nosso mundo a experiência e revelação de Jesus, na conotação de proximidade, ternura e confiança que emergem do termo $A b b a$, possivelmente sua tradução mais adequada consistisse na invocação de Deus como Mãe, o que ancoraria principalmente a visão feminista/mulherista.

\section{Que estás nos céus:}

Este verso é praticamente coincidente em quase todas as traduções bíblicas, e procura recordar o Cristão que, apesar da proximidade com o homem, não significa que não continue sendo o Outro, o Transcendente, o Mistério (FIORES; GOFFI, 1989, p. 882). Nessa tradução que se quer universal, chama a atenção o plural nos céus. As questões que se referem ao termo cén como tradução do hebraico samayim tomam corpo na medida em que o termo hebraico tinha origem e sentidos incertos, o que pode dar uma noção de firmamento ou de transcendente. Em inglês, por exemplo, há heaven para o sentido transcendente e sky para o sentido material da palavra. Por essa razão, nas línguas em que a distinção não é feita lexicalmente, tem-se buscado explicar o termo, o que tem aumentado as edições com paratexto.

Born (1987, p. 163) procura separar áreas, definindo céu como firmamento dentro da cosmologia e como a morada de Deus na teologia. 
Mackenzie (1984) prefere esclarecer que na concepção semítica antiga, dividia-se o céu em vários níveis ou estágios que variavam de um povo para outro e de um período para outro. Dessa maneira, o entendimento que temos hoje de céu parece ter sido insuficiente para essa tradução, que buscou no plural novas possibilidades para entendimento do termo.

\section{Santificado seja o teu nome:}

Antes de analisar o aspecto semântico da palavra santificado, é mister entender o que se entendia por nome. Fiores e Goffi (1989) esclarecem que, na linguagem da Bíblia, o nome expressa a realidade íntima da pessoa, sendo que conhecer o nome é entrar no mistério de quem o possui e chegar a dominar este mistério. Nesse sentido, parece haver uma metonímia por tomarmos o nome como sendo Deus, e acredito que se está procurando não exatamente santificar algo que em si já o é, mas, sobretudo, tirar esse nome, esse Ser, do que é profano, ou mesmo exaltá-lo.

Nesse ponto, faz sentido a passiva sintética imperativa santificado seja. Ou ainda, como há uma diferença entre esse Deus que não é Iahweh, mas $A b b a$, "santificar o nome significa que todos os homens o aceitem como Pai, que se aproximem dele partindo desta filiação e que assim o proclamem" (FIORES; GOFFI, 1989, p. 882). Nesse caso, existe também uma estreita ligação com o aspecto etimológico da palavra santo. Born (1987) explica que santo vem do hebraico qados e qodes (santidade), que, por sua vez, vem de qadad (cortar em sentido cultual), ser afastado, separado do impuro, do profano (hoi). Mackenzie (1984, p. 847) também nos explica que, no caso da raiz em hebreu KDSH, significa, em conformidade com a maioria dos estudiosos, separar, mas, no uso, divindade.

\section{Venha o teu reino:}

O chamamento deste verso parece ser um claro pedido de um reino de perfeição imaterial representado por Deus em nosso mundo. Para Fiores e Goffi (1989, p. 882-883), mais do que reino, trata-se de reinado de Deus sobre quem aceita a pessoa de Seu filho como mensageiro. E esse reinado consiste em sua soberania sobre cada um dos homens, uma vez que esse reinado não se manifestou em todo o seu 
esplendor. Nessa tradução, omite-se a nós, uma expressão quase consensual nas traduções do Pai Nosso. Aqui, parece que a omissão provém da crença de que, por ser verdade que quem pede juntamente com os outros constituirá esse nós, não precisa ser escrito de maneira explícita. E talvez a maneira mais simples de explicar esse fato seja a crença de que Jesus retornará.

\section{Seja feita a tua vontade, assim na terra como no céu}

Atualmente, com muita força, mas proveniente de pensamento muito antigo, acredita-se que, como Deus é o único Ser Perfeito, que, por sua onisciência e onipotência, é capaz de julgar com retidão, pode-se entregar a vida a Ele, que tudo se resolverá4. Vale lembrar que esta petição é exclusiva de Mateus. Fiores e Goffi (1989, p. 883) acreditam que foi um esforço de Mateus para "consertar" a própria oração de Jesus interpretando o sentido do pedido anterior, em que se deveria cumprir o projeto de reinado de Deus na terra com a perfeição daquele no céu. Nesse sentido, a vontade de que se fala é a de cumprimento dos ensinamentos de Cristo. Os autores ainda esclarecem que, no tempo de Jesus, a petição orientava-se no sentido de que o projeto messiânico do Pai fosse adiante e resumia a essência da santidade cristã.

\section{O pão nosso de cada dia nos dá hoje;}

Nesse verso, o grande problema envolve a palavra pão e suas possibilidades semânticas, e talvez também uma questão de diferenças entre Mateus e Lucas. Mateus trabalha com uma noção de pão que será dado hoje (sémeron), como se verifica aqui, e Lucas especifica que será dado a cada dia (kath eméran). Talvez as traduções estejam tentando manter as duas e por isso trabalham com pão de cada dia. Para a Bíblia de Jerusalém, à página 1848, de cada dia é uma tradução tradicional e provável de uma palavra difícil, para a qual outras traduções foram

\footnotetext{
${ }^{4}$ Note-se, pela conjuntura socioeconômica, o quanto todos se agarram nesse pressuposto ideológico e o quanto as igrejas se apegam a ele para competirem entre si no mercado religioso atual.
} 
propostas, como necessário à subsistência e de amanhã. E ela esclarece ainda que a ideia fundamental é a de pedir a Deus sustento indispensável à vida material, mais nada senão isso. $\mathrm{Na}$ Igreja, refere-se à nutrição da fé: o pão da palavra de Deus e o pão eucarístico.

Chevalier e Gheerbrant (2001, p. 681-682) mostram claramente os problemas relacionados às interpretações da palavra pão. Enquanto pode significar o material, pode ser tomada em sentido transcendental, como alimento espiritual e, ao que parece, não há uma maneira de desfazer esse dilema que, no texto bíblico, ora pende para o primeiro sentido, ora para o segundo. Born (1989) registra apenas o sentido material, sem o recurso do paratexto.

Numa interpretação radical como a de Silva (2000), o sentido material prevalece, uma vez que, na época de Jesus, a fome era avassaladora e assolava a maioria das pessoas que, inclusive, o tinham como alimento básico e indispensável. Hoje, material ou transcendente, a duplicidade continua e faz sentido em ambos os casos devido ao nosso contexto, de inúmeros e diversificados problemas, má distribuição de renda, miséria e fome.

\section{E perdoa-nos as nossas dívidas,}

Fiores e Goffi (1989), como possuem uma clara envergadura eclesiástica, trabalham com a noção de que Jesus sabe que o discípulo pode não corresponder às exigências do reino e às do Pai, reveladas nas escrituras e, por isso, precisa do pedido de perdão. Contudo, no contexto popular, parece ganhar a duplicidade do termo ao representar, ao mesmo tempo, o pecado transcendental e as dívidas materiais (como nos fala SILVA, 2000, a respeito da época de Cristo), pois não é raro que se reze para acabar com dívidas no sentido material. Aqui, parece ganhar destaque o aspecto econômico inerente a muitas igrejas evangélicas, que afirmam poder resolver problemas materiais em nome de Jesus.

A visão de Silva (2000), por exemplo, leva em conta uma percepção social do Pai Nosso acoplada a uma visão antropológica dentro da qual o homem passa a ter papel preponderante como ser animal, social, político, moral e ideológico, estreitamente ligado a seu meio, a sua cultura e a sua época. Essa visão é bastante abrangente, por não se 
excluírem simplesmente quaisquer pontos de vista ou possibilidades de leitura, mas buscar abarcá-los dentro de uma visão crítica capaz talvez de explicitar o contexto que propiciou a produção do texto. Em outras palavras, a tradução do Pai Nosso feita por esse autor busca subsídios na sociedade que estava por trás do texto e, por isso, refletida nele, num contraponto a uma visão teológica tradicional que, segundo ele, não conseguiu adequadamente responder várias questões. Como exemplo, podemos citar que, devido a fatores sociolinguísticos e antropológicos, Silva (2000) traduz perdoai as nossas dividas como não nos ponha em teste, com a ideia anacrônica de que não deixar cair em tentação remetia ao contexto em que o camponês era desapropriado de suas terras devido às constantes extorsões que o levavam a ter dívidas para com o Estado. $\mathrm{O}$ maligno, o mal, nesse sentido, nada tem de sobrenatural como nas conotações do Pai Nosso rezado hoje; era simplesmente o juiz que daria o veredicto final: a expropriação ou não das terras.

Apesar do choque proveniente de uma visão pré-formada e acabada da tradução/interpretação do Pai Nosso, os indícios são fortes e relevantes para estudos críticos de tradução, principalmente quando existe uma interação entre todos os elementos que influem no processo de produção, distribuição e consumo do produto final: o texto traduzido. Dessa maneira, percebe-se que, nesse caso específico, foram levadas em conta as diferenças entre o mundo mediterrâneo no qual o Novo Testamento foi gestado e o Ocidente moderno. E é nesse sentido que Silva (2000), de posse de informações socioantropológicas que mostravam uma época de miséria, escravismo e extorsões, formadora de uma audiência bastante singular para Jesus, traz uma visão divergente das traduções consideradas canônicas, inclusive a que é proposta como objeto de análise aqui.

\section{Assim como nós perdoamos aos nossos devedores.}

Nessa parte, parece haver uma referência ao mandamento de ame a seu próximo como a si mesmo, inclusive seus inimigos. Fiores e Goffi (1989, p. 885) trabalham contestando a possibilidade de pensar assim como nós perdoamos como uma condição não verdadeira para o perdão de Deus às nossas dívidas, do pedido anterior. Para eles, está-se procurando ensinar 
o discípulo que se atreve a pedir perdão ao Pai para si, que terá de mostrar para com o outro a mesma atitude que gostaria que o Pai tivesse para com ele. Mas deve-se ressaltar que o matiz dual da palavra devedor neste verso é o mesmo da palavra dívidas do verso anterior.

\section{E não nos induzas à tentação;}

Aqui percebemos uma conotação interessante pela mudança do tradicional deixar cair por induziir, que nas versões latinas e inglesas é mantida na própria escolha lexical (inducas/lead). Para autores de orientação teológica, tentação tem uma conotação próxima à de pecado (cf. FIORES; GOFFI, 1989), mas é inegável a noção atual de desvirtualização ou desvio do caminho do bem, por uma força do mal, normalmente personificada na figura do demônio (Catolicismo), do encosto (evangélicos, principalmente os pentecostalistas), de espíritos atrasados ou maus (Espiritismo) e de alguns tipos de exus/quiumbas (Umbanda, Quimbanda e Candomblé5). Contudo, o verbo induzir em português, como no latino inducere, traz sua noção original de conduzir, levar para dentro, o que justificaria a ideia que levou alguns tradutores a tomar tentação como prova.

\section{mas livra-nos do mal;}

O uso da conjunção adversativa mas está discursivamente mostrando que, se os fiéis forem induzidos à tentação, poderão não conseguir resistir a elas. A contrariedade, então, estaria presente na natureza pecadora que não deveria ser posta em prova. Isso justificaria a escolha de mal como proveniente da ideologia que personifica o mal num demônio que se contrapõe a Deus.

\footnotetext{
5 Partimos de uma visão generalista, mas existem algumas diferenças sobre a figura de Exu na concepção dessas religiões. A Umbanda trabalha com uma escala que concebe alguns tipos de exus como guardiões e, por isso, de extrema importância; a Quimbanda, em geral, pouco os distingue, uma vez que se dedica quase exclusivamente a seu culto, e o Candomblé vê Exu como um mensageiro dos orixás ou como a personificação do princípio da transformação. Para um melhor entendimento desses pontos, sugerimos a leitura de Silva (1994) e Augras (1983).
}

CARMO - Implicações socioculturais e ideológicas... 


\section{porque teu é o Reino, e o poder, e a glória para sempre.} Amém.

Esse término, que não está presente em nenhuma das versõesfonte da Bíblia, justifica-se, como em nota de rodapé a Bíblia de Jerusalém (1985, p. 1849) nos esclarece, por uma questão de influência litúrgica.

\section{CONSIDERAÇÕES FINAIS}

Explicar detalhes, construindo um paratexto para o Pai Nosso, não é uma tarefa fácil, pois pressupõe um domínio bastante vasto do contexto, da cultura e das línguas em que originalmente os textos bíblicos foram escritos; do contexto, da cultura e das línguas para os quais foram traduzidos e do uso que a comunidade de recepção faz ou tende a fazer do produto final.

Não obstante essas dificuldades, este trabalho consiste mais em um esforço de tentar entender essa oração como ela tem sido utilizada hoje dentro de uma proposta que se quer abrangente, tendo um olhar complicadamente universalizante, que, contrariamente a inúmeras revisões e versões, procura apagar marcas capazes de identificar grupos a partir de suas ideologias. Talvez seja uma busca de um ponto de vista ecumênico, que ainda parece ser uma utopia.

Por essa razão, essa leitura procurou mostrar variados pontos de vista, mas o contexto socioeconômico atual tende a redirecionar o sentido de itens lexicais, principalmente os de tentação e mal para um mesmo ponto. Parece que, em sentido ecumênico, como a fonte do texto analisado procura ter ${ }^{6}$, a oração do Pai Nosso universaliza os anseios de centenas de milhares de pessoas no mundo que sofrem com a má distribuição de renda, com a miséria, com a fome, com o preconceito, dentre outros, pois serve como um conforto, um alento, como um sustento material, imaterial e incondicional àquele que não tem mais a quem ou a que recorrer.

${ }^{6}$ A distribuição do exemplar é, de acordo com a apresentação do livro, mundial. 
O que se pode perceber também é que grande parte das traduções da Bíblia são de cunho literário ou sociocultural, sendo que, conforme apontou Silva (2000), no primeiro caso privilegiam-se os recursos expressivos e, no segundo, os aspectos sociais, ligados, por sua vez, a aspectos políticos. Essa ligação política pode ser vista como uma forma de engajamento ideológico que demonstra a perspectiva específica que orienta a tradução. No caso de Silva (2000), cuja tradução é considerada radical, deixa-se claro que a visão de agora é extremamente diferente da visão da época de produção do texto.

Dessa maneira, não apenas diferentes pontos de vista e orientações das traduções da Bíblia, mas também a dificuldade de estabelecer uma relação harmônica entre aspectos diferentes como o literário e o sagrado, têm a ver tanto com a língua de chegada quanto com a cultura de quem vai receber a tradução.

Em outra instância, o que nossas reflexões indicam é que as escolhas lexicais revelam as características do lugar de produção e as diferenças de leitura provocadas pelo lugar do leitor/receptor das mensagens, que pertence a outra época e a outra cultura, bem como o lugar do tradutor como mediador desse processo.

\section{REFERÊNCIAS}

AUGRAS, M. O duplo e a metamorfose: a identidade mítica em comunidades nagô. Petrópolis: Vozes, 1983.

BARRERA, J. T. A Bíblia Judaica e a Bíblia Cristã: introdução à história da Bíblia. Tradução de Ramiro Mincato. Petrópolis: Vozes, 2000.

BAYLY, D. Anti-unisex backlash: liberal theologians seek to preserve a literal bible translation, even at the risk of patriarckalism. Disponível em:

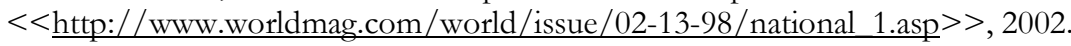
Acesso em: 6 ago. 2002.

BIBLIA DE JERUSALÉM. São Paulo: Paulinas, 1985.

BORN, A.V. D. Dicionário enciclopédico da Bíblia. Petrópolis, RJ: Vozes, 1987.

BRYANT, M. What is a "sacred text"? and why do we need one?

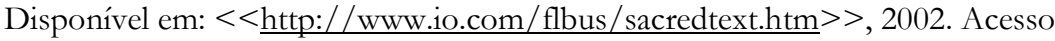
em: 6 ago. 2002.

CARMO - Implicações socioculturais e ideológicas... 
CARMO, C. M. Aspectos híbridos do discurso da Igreja Universal do Reino de Deus (IURD) na mídia televisiva: entre a religião e o marketing. 2001. 235f. Dissertação (Mestrado em Estudos Linguísticos) - Faculdade de Letras, Universidade Federal de Minas Gerais, Belo Horizonte.

CERESKO, A. R. Introdução ao Antigo Testamento numa perspectiva libertadora. Tradução de José Raimundo Vidigal. São Paulo: Paulus, 1996.

CIPRIANI, V. M. et al. Outras Leituras. In: SILVA, C. M. D. Metodologia de exegese bíblica. São Paulo: Paulinas, 2000. p. 317-354.

CHEVALIER, J.; GHEERBRANT, A. Dicionário de símbolos: mitos, sonhos, costumes, gestos, figuras, cores, números. Rio de Janeiro: José Olympio, 2001.

CUNHA, J. G. Dicionário etimológico nova fronteira da língua portuguesa. Rio de Janeiro: Nova Fronteira, 1986.

DEIST, F. E. (Ed.). The material culture of the Bible: an introduction. Sheffield: Sheffield Academic Press, 2000.

FERNANDES, R. C. et al. Novo nascimento: os evangélicos em casa, na igreja e na política. Rio de Janeiro: Mauad, 1998.

FIORES, S.; GOFFI, T. Dicionário de espiritualidade. São Paulo: Paulinas, 1989.

FRISOTTI, H. Povo negro e bíblia: retomada histórica. Mosaicos da Bíblia, Koinonia. São Paulo, n. 17, p. 11-22, jan/mar 1995.

FRISOTTI, H. Povo negro e bíblia: caminhos de aproximação, II. Disponível em: $<<$ http://www.uca.edu.ni/koinonia/relat/155.htm >>, 2002. Acesso em: 6 ago. 2002.

GABEL, J. B.; WHEELER, C. B. A Bíblia como Literatura: uma introdução. Tradução de Adail Ubirajara Sobral e Maria Stela Gonçalves. São Paulo, Loyola, 1993.

GODDARD, B. L. The footnoting system. In: POLCYN, R. P. (Ed.). The NIV: the making of a contemporary translation. Colorado Springs: International Bible Society, 1999. p. 32-44.

GOHN, C. Pesquisas em torno de textos sensíveis: os livros sagrados. In: PAGANO, A. S. (Org.). Metodologias de pesquisa em tradução. Belo Horizonte: Faculdade de Letras, UFMG, 2001. p. 147-170. 
GOT'TWALD, N. K. Introdução socioliterária à Bíblia Hebraica. Tradução de Anacleto Alvarez. São Paulo: Paulus, 1997.

HELMINIAK, D. A. What the Bible really says about homosexuality. NJ: Alamo Square Press, [1994] 2000.

KALLAND, E. S. How the Hebrew and Aramaic Old Testament text was established. In: POLCYN, R. P. (Ed.). The NIV: the making of a contemporary translation. Colorado Springs: International Bible Society, 1999. p. 45-53.

NOVO TESTAMENTO, SALMOS, PROVÉRBIOS. S.d. Nashville, Tennessee, U.S.A.: The Gideons International.

MCDONALD, L. M.; SANDERS, J. A. (Eds.) The canon debate. Peabody, MA: Hendrickson Publishers, 2002.

MACKENZIE, J. L. Dicionário bíblico. São Paulo: Paulinas, 1984.

MAIER, C. Reviewing and criticism. In: BAKER, M. (Ed.) Routledge Encyclopedia of Translation Studies. London and New York: Routledge, 2000. p. 205-210.

MAINGUENEAU, D. Termos-chave da análise do discurso. Belo Horizonte: UFMG, 2000.

MUGAMBI, J. N. K. Biblical hermeneutics: an afrocentric perspective.

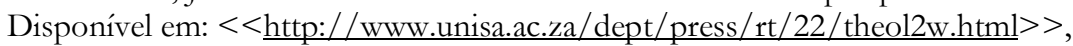
2002. Acesso em: 6 ago. 2002.

MULLINS, P. Sacred text in the sea of texts: the Bible in North American electronic culture. In: ESS, C. (Ed.). Philosophical perspectives in computermediated communication. Albany: Suny Press, 1996. p. 271-302.

NIDA. E. A. Bible translation. In: BAKER, M. (Ed.) Routledge Encyclopedia of Translation Studies. London and New York: Routledge, 2000. p. 22-28.

NORD, C. A functional typology of translations. In TROSBORG, A. (Ed.). Text typology and translation. Amsterdam, Philadelphia: John Benjamins, 1997. p. 43-66.

PIRES, J. M. O deus da vida nas comunidades afro-americanas. Disponível em: <<http://www.peacelink.it/zumbi/afro/atab/cons03.html >> 2002.

Acesso em: 6 ago. 2002.

REIMER, H. A casa global: sobre textos bíblicos em perspectiva ecológica no ensino religioso. In: SILVA, V. (Ed.). Ensino religioso. Educação centrada na vida. Subsídios para a formação de professores. São Paulo: Paulinas, 2004. p. 49-72. 
SHEELEY, S. M.; NASH, R. N. Choosing a Bible: a guide to modern English translations and editions. Nashville: Abingdon Press, 1999.

SILVA, A. J. Leitura sócio-antropológica. In: SILVA, C. M. D. (Org.).

Metodologia de exegese bíblica. São Paulo: Paulinas, 2000. p. 355-361.

SILVA, V. G. Candomblé e umbanda: caminhos da devoção brasileira. São Paulo: Ática, 1994.

SILVA, N. O. Traduzindo a Bíblia para povos indígenas. In: LIDÓRIO, R. (Org.). Indígenas do Brasil: avaliando a missão da igreja. Viçosa: Ultimato, 2005. p. 205-216.

SIMMS, K. Introduction. In: SIMMS, K. (Ed.). Translating sensitive texts: linguistic aspects. Amsterdam: Atlanta, GA., 1997. p. 01-26.

SISLEY, J. Transforming the canon: biblical narrative and popular culture. Disponível em:

$<<$ http://www.researchcenter.org/library/publicationsarchives/keyarticlespape rs/joysisley/joysisleycanon.htm >>, 2002. Acesso em: 6 ago. 2002.

TYMOCZKO, M. Computadorized corpora and the future of the translation studies. Meta, v. 43, n. 4, p. 652-659, dec. 1998.

Recebido em 09/04/10. Aprovado em 30/01/11.

Title: Sociocultural and Ideological Implications in the Translation of Sensitive Texts: Reflections from The Lord's Prayer and its Multiple Reading Possibilities

Author: Cláudio Márcio do Carmo

Abstract:The present work employs the explanatory tool paratext for translations of sacred texts, also considered sensitive texts due to its peculiarities. While building a paratext the initial focus was on different perspectives in order to problematize both the process of translation and different versions generated for particular publics. As an analytical category, lexical choices were sellected since it was assumed that there are ideological and sociocultural implications, which underlie the semantics of each lexical choice made, showing what point of view guided the translation, since such implications are often put more clearly in the form of a paratext that can guide the reader. As an example, a paratext was produced based on a translation of The Lord's Prayer that intends to be universal.

Keywords: Paratext. Translation. The Lord's Prayer.

Titulo: Implicaciones socioculturales e ideologicas de la traducción de textos sensibles: reflexiones a partir del Padre Nuestro y sus múltiples posibilidades de lectura

Autor: Cláudio Márcio do Carmo

Resumen: Este trabajo utiliza el recurso explicativo paratexto en el caso de traducciones de textos sagrados, también considerados textos sensibles dadas las peculiaridades que les son inherentes. 
Construyendo un paratexto, procuramos focalizar en un primer momento diferentes perspectivas de forma a problematizar tanto el proceso traslacional en cuanto a las diferentes versiones generadas para públicos particulares. Como categoría de análisis, optamos por las elecciones lexicales, partiendo del supuesto de que existen implicaciones socioculturales e ideológicas que subyacen a la semántica de cada item lexical elegido, mostrando cual es el punto de vista que orientó la traducción, porque esas implicaciones, muchas veces, son colocadas de manera más nítida en la forma de un paratexto que pueda conducir al lector. Como ejemplo, producimos un paratexto basado en una traducción que se pretende universal para la oración del Padre Nuestro según Mateo.

Palabras-clave: Paratexto. Traducción. Padre Nuestro.

CARMO - Implicações socioculturais e ideológicas... 